\title{
Toward the integration of brownfield rehabilitation and planning methodologies: case study of Keihin Industrial Area, Tokyo, Japan
}

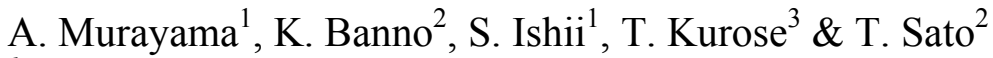 \\ ${ }^{I}$ Center for Sustainable Urban Regeneration, School of Engineering, \\ The University of Tokyo, Japan \\ ${ }^{2}$ Engineering \& Risk Services Corporation, Japan \\ ${ }^{3}$ Department of Urban Engineering, School of Engineering, \\ The University of Tokyo, Japan
}

\begin{abstract}
Keihin Industrial Area (KIA) is the largest industrial area in Japan that has supported the country's rapid economic growth in the twentieth century. Now KIA calls for the integrated methodology of brownfield regeneration and planning as it gradually changes from the heavy industrial base to a new urban area that potentially contains research and development institutions, light industry, business and commercial facilities, housing and other uses. The paper, after introducing the current framework for brownfield rehabilitation in Japan and the current planning of KIA, presents key factors to be considered in establishing an integrated methodology for KIA regeneration.

Keywords: Tokyo, brownfield rehabilitation, land use planning, methodology.
\end{abstract}

\section{Introduction}

Tokyo is the largest urban region in the world containing more than 34 million inhabitants in the four prefectures of Tokyo, Kanagawa, Chiba and Saitama [1] (Figure 1). Industrial areas of various sizes are dispersed throughout the region, but the largest concentration is in Tokyo Bay Waterfront Area that holds Keihin Industrial Area (4,400 ha) and Keiyo Industrial Area (4,700 ha). These industrial areas were the engines of Japan's economic growth in the twentieth century, but 
they are now experiencing a gradual change as they entered the globalizing twenty-first century. Figure 2 shows the change of production by major types of industry in Keihin Industrial Area. The production of the industrial area hit its peak in 1985 and is dropping afterwards. Similar trend can be observed in Keiyo Industrial Area. Under these circumstances, many parts of Tokyo Bay Waterfront Area have been redeveloped to mixed-use (i.e. residential and commercial) urban areas such as Makuhari, Urayasu, Odaiba, Shiodome, Tennouzu and Minatomirai, or to residential areas such as Toyosu, Shibaura and Konan (Figure1). However, the vast industrial areas still remain.

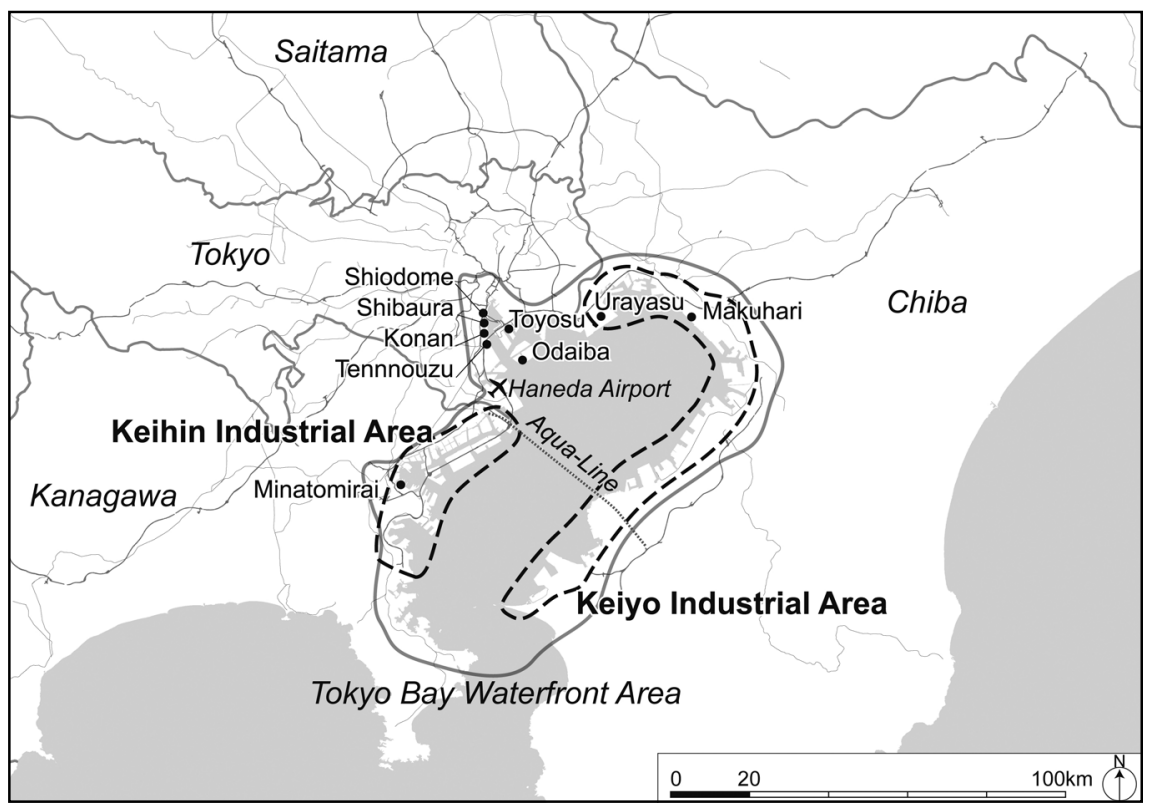

Figure 1: $\quad$ Map of Tokyo region with Keihin and Keiyo Industrial Areas.

This study focuses on City of Yokohama part (2,200 ha) of Keihin Industrial Area (KIA), one of the areas that have not been redeveloped to either mixed-use or residential areas. After the opening of the Port of Yokohama in 1859, KIA was developed through the private reclamation projects in the 1920 s by a businessman Soichiro Asano. After World War I, major cement, steel, electronics, oil, wharf and warehouse companies located their plants in KIA. These plants, while driving Japan's economy, are thought to have left behind various hazardous substances in the soil. KIA kept on expanding even after the World War II until the completion of Daikoku Harbor in 1990.

Recently, there has been a drastic movement among companies in KIA such as the mergers of oil and steel companies or relocation of plants to foreign countries, which results in the generation of potential sites for redevelopment. On the other hand, research and development institutions have been located in KIA such as RIKEN Yokohama Institute and Yokohama City University 
International Graduate School of Arts and Sciences in Suehirocho, introducing new land uses to the area.

Thus KIA calls for the integrated methodology of brownfield regeneration and planning as it gradually evolves from the heavy industrial base to a new urban area that potentially accommodates research and development institutions, light industry, business and commercial facilities, housing and other uses.

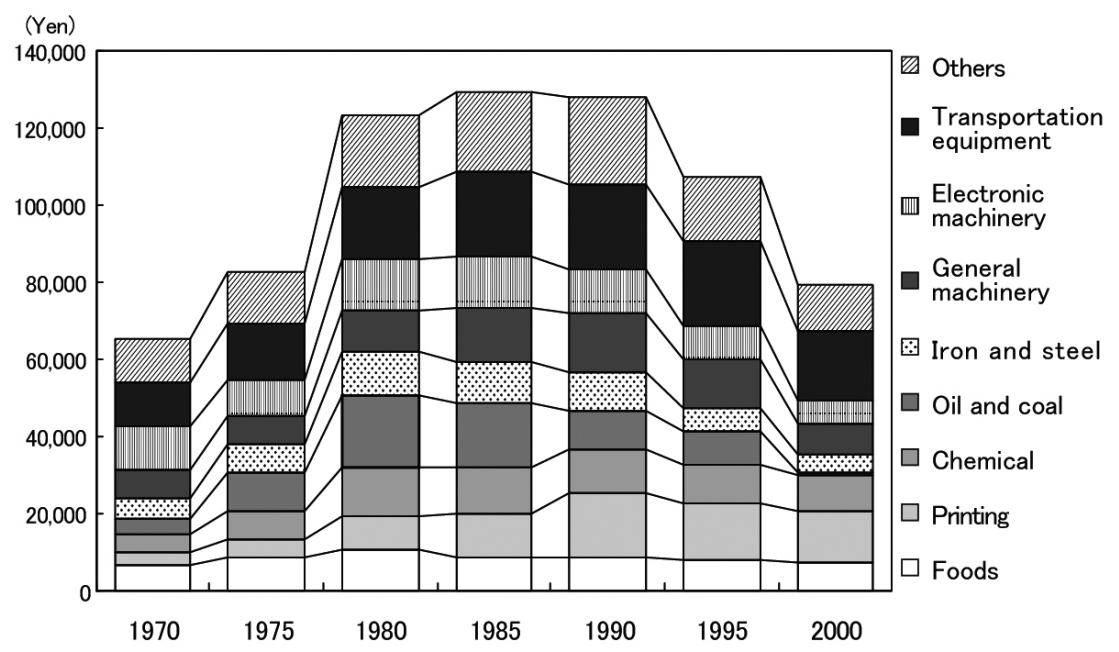

Figure 2: $\quad$ Production by major types of industry in Keihin Industrial Area [2].

\section{Current framework for brownfield rehabilitation}

"Brownfield" is not officially defined in Japan. To avoid misunderstanding of this technical term, it is defined for this paper as "contaminated land potentially to be developed".

\subsection{Soil Contamination Countermeasures Law and local regulations}

From the latter half of the 1980s and to the 1990s, buried industrial wastes and the surrounding contaminated soil were often unearthed at closed factory sites when they were redeveloped to residential apartments or commercial complexes. In response to this situation, Government of Japan set up a series of legislative measures such as the National Soil Environmental Standards in 1991, the Guidelines for Site Assessment and Response Actions in 1996 and the Soil Contamination Countermeasures Law (SCCL) in 2003.

Under the SCCL, there are two cases where landowners are obligated to carry out an environmental site assessment and remediation. Firstly, the owner of a hazardous wastewater treatment facility, normally registered to prefectural environmental administrator's office, has to conduct a site assessment when closing the facility. Secondly, the owner of a contaminated land property needs 
to take responsible actions when human health is threatened by polluted groundwater spreading from the site to the neighbouring environment. There is an option only for an industrial manufacturing site owner, however, to postpone conducting a site assessment in case where the land use remains the same for the future development.

In addition to the national regulation mentioned above, there are local regulations implemented by municipal statutory authorities. The purpose of local regulation is not to deregulate the SCCL but to help provide more opportunities or create more situations to require site assessments or to force landowners to disclose appropriate site information from the risk communication perspective. City of Yokohama covering a part of KIA has its own regulation. This requires: 1) analyses of dioxins in addition to the hazardous substances designated under the SCCL and 2) manufacturing companies to conduct site assessments and report to the city when they plan to conduct excavation works or close their factories.

\subsection{Effects of the SCCL on brownfield rehabilitation}

The survey conducted by Ministry of the Environment, Japan reports that the number of sites where site assessment was conducted under the SCCL was 93 [3] (Table 1), whereas the statistics provided by the Geo-Environmental Protection Center (GEPC) shows that the number of site assessments conducted by private contractors was as many as 4,281 [4], both of which were compiled for Fiscal Year 2003. The number reported by GEPC includes the sites unreported to any governmental agencies and the SCCL sites. This comparison suggests that the SCCL data represents only a small portion of contaminated or potentially contaminated sites, implying that the amendment of the law may be required in the future.

Table 1: $\quad$ Assessments conducted under the SCCL in FY 2003.

\begin{tabular}{l|c}
\hline SCCL assessments & Number of cases \\
\hline \hline Facility closures that trigger SCCL assessments & 590 \\
\hline Completed SCCL assessments & 63 \\
\hline (The number of contaminated sites found) & $(22)$ \\
\hline Ongoing SCCL assessments & 30 \\
\hline Pended SCCL assessments & 491 \\
\hline
\end{tabular}

The SCCL basically requires a "contain and control" approach for soil contamination countermeasures. For example, when a land is contaminated with heavy metal compounds, the landowner may be required first to construct asphalt pavement or soil cap layer on top of the contaminated soil to prevent harmful dusts from being inhaled by humans. If there is a risk of metal leachate migrating beyond the property boundary, groundwater flow must be controlled by the installation of sheet piles or the equivalent, and the contamination levels must be monitored to guarantee the effectiveness of "contain and control". As 
for volatile organic compounds such as benzene or trichloroethylene, the SCCL requires groundwater controls. Vapour coming out from extended plumes has not been addressed under the SCCL so far since its risk to human health has not been well examined.

The SCCL has also introduced a grant that provides funding for a site assessment and restoration in case where a landowner is not a polluter and no identified polluter is affirmed to exist. This incentive has a great potential to encourage brownfields rehabilitation. However, it has never been utilized since the SCCL was enacted.

\subsection{Current situation on site cleanup}

Although the SCCL basically requires "contain and control" approach for countermeasures, more than 80 percent of the countermeasures that have been adopted in real site restoration ended up in a "dig and haul", according to the survey conducted by Ministry of the Environment [3] (Table 2).

Table 2: $\quad$ Countermeasure methods (multiple answers possible).

\begin{tabular}{l|c}
\hline Countermeasure methods & Number of sites \\
\hline \hline Groundwater monitoring & $300(6)$ \\
\hline Soil contamination removal & $1127(17)$ \\
\hline In-situ containment & $60(1)$ \\
\hline Liner sheet installation & $2(0)$ \\
\hline In-situ solidification/stabilization & $56(0)$ \\
\hline On-site stabilization & $45(0)$ \\
\hline Concrete vault containment & $35(0)$ \\
\hline Soil capping & $66(1)$ \\
\hline Pavement & $122(2)$ \\
\hline Off-limits advisory & $58(2)$ \\
\hline Others & $301(0)$ \\
\hline The total number of respondents & $1307(19)$ \\
\hline
\end{tabular}

Note: The numbers in the parentheses represent the SCCL sites.

This table is assembled with the survey results from1991 to 2003.

The survey report doesn't explain why soil contamination removal became such a widely adopted countermeasure method, but the following factors seem to support this cleanup trend: 1) The contaminated soil recycling business have been established, using the well-established domestic land and sea transportation networks, among the soil treatment facilities which utilize separation, evaporation or combustion methods, and 2) most of the former industrialized area in and around the urban areas have been converted into residential area, where prospective purchasers tend to be aware of stigma and to expect so called "complete cleanups". 
A "dig and haul" approach is not necessarily the best solution to make brownfield redevelopment cost-effective and environmentally and socially beneficial to communities. More collaborative works should be carried out between planners and environmental specialists to share the comprehensive scopes and to design appropriate contaminated site rehabilitation schemes.

\section{Planning and existing conditions}

\subsection{Past and current regional and local planning}

Many planning studies for KIA regeneration have been conducted since the 1970s. In the 1970s, several studies were conducted on Tokyo Bay Aqua-Line, the trans-bay expressway that connects Keihin and Keiyo Industrial. No studies on redevelopment have been conducted in this era of rapid growth. In the 1980s, National Land Agency (now integrated to Ministry of Land, Infrastructure and Transport), Government of Japan, have conducted numerous studies on redevelopment in Tokyo Bay Waterfront Area. The government at that time was promoting urban redevelopment to boost the country's economy and various areas in Tokyo Bay Waterfront Area were among the targets. Many of the new mixed-use urban areas and residential areas were planned in the 1980s, slowly developed in the recession of the 1990s and completed around 2000.

Corresponding to such regional planning studies on urban redevelopment by the national government, City of Kawasaki and City of Yokohama partly supported by the national and the prefectural governments initiated several local planning studies to set a new vision for KIA and to implement necessary projects. The major characteristic of the studies by the cities is that they focused on industry-related redevelopment and infrastructure projects instead of urban redevelopment projects. The cities have been promoting industry-related growth to aim for more tax revenues.

The latest plans for KIA are Keihin Waterfront Area Regeneration Framework [5] and Keihin Waterfront Area Regeneration Master Plan [6]. The framework stressed on (1) industrial revitalization by promoting new industries, developing Foreign Access Zone (FAZ) facilities for foreign trades and attracting businesses to underutilized sites, and on (2) infrastructure projects including the efficient use of the existing freight railway tracks, the improvement of the metropolitan expressway and the development of green spaces for disaster prevention. The master plan set out more detailed policies for the following six zones within Yokohama City limit of KIA (Figure 3).

Zone 1: Inland urban regeneration in cooperation with waterfront regeneration Zone 2: Promotion of land use transition to create a mixed-use urban area Zone 3: Advanced manufacturing center with global competitiveness Zone 4: Advanced research and development center related to manufacturing Zone 5: General distribution center Zone 6: Advanced and efficient manufacturing center.

It also set out issue specific policies for railway and roads, for creating attractive space including historic conservation, industrial tourism and landscaping, and for 
improving performance in case of disaster. Furthermore, the following three districts are designated as priority districts.

Shinurashima and Moriyacho: Promotion of land use transition to create a mixed-use urban area by improving railway and road infrastructure, creating job opportunities and landscaping rivers and canals.

Daikokucho: The deregulation of industry-related restrictions and the improvement of arterial roads to further improve existing industrial functions and to enhance global competitiveness.

Suehirocho: Development of a new research and development center by attracting advanced small-medium size businesses and research institutions, effectively using existing freight and passenger railway tracks, improving road network and landscaping waterfront.

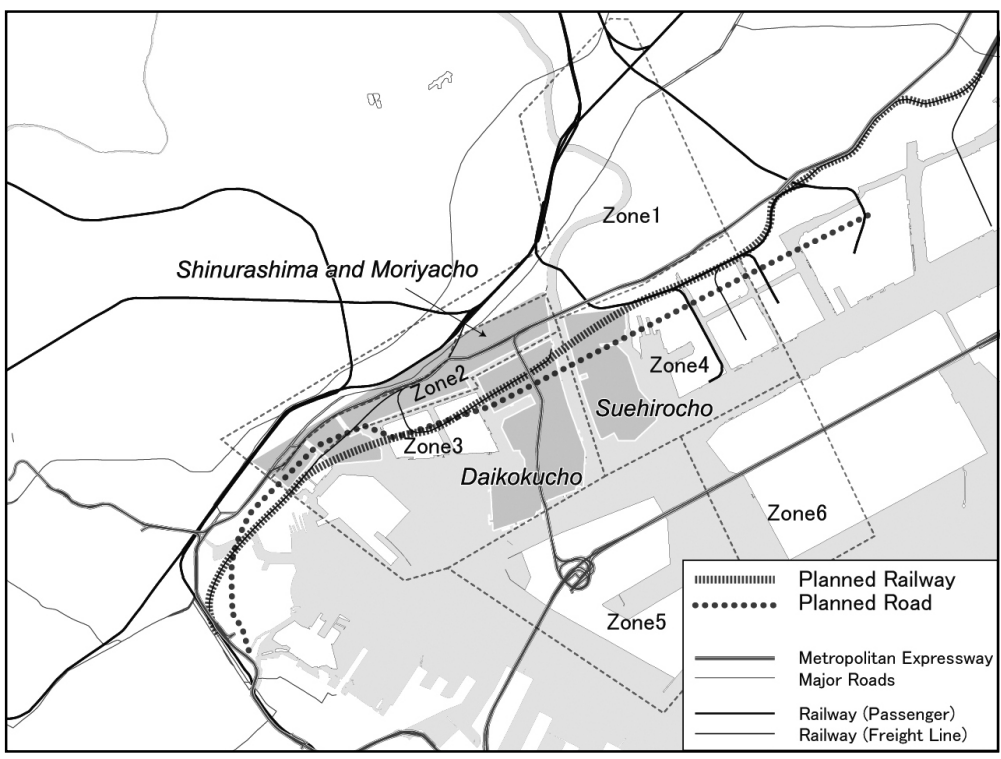

Figure 3: Six zones, three priority districts and improvement of railway and road infrastructures [6].

Thus, broad framework and issue specific policies for Yokohama City part of KIA, more detailed policies for the six zones within and development policies for the three priority districts are established through the planning efforts. However, explicit objectives such as employment and population targets, environmental standards, level of transportation services and visual image of urban design for the whole area are not yet clear to promote redevelopment activities. Objectives and images are considered on an individual project basis. To set forward the regeneration of KIA, the authors think it necessary to develop a comprehensive plan which includes the elements of industrial development, land use, transportation, building types and urban design of public space. 


\subsection{Existing conditions}

\subsubsection{Land use}

Figure 4 shows that six zones of KIA (City of Yokohama part only) lost more than 175 ha of industrial uses from 1985 to 1995 . In zones 1 and 2 bounded on inland urban area, industrial uses are changed to residential or commercial uses. In zones 3 and 5, the increase of freight uses can be observed. The increase of vacant sites is also significant adding up to approximately 105 ha in 2002 . Figure 5 shows the distribution of twelve underutilized sites as of 2002 with the proposed land use transition. City of Yokohama proposed these directions for land use transition based on the recognition that nanotechnology, biotechnology and information technology are the new industries that can support KIA, but this does not impose any land use or redevelopment restrictions.

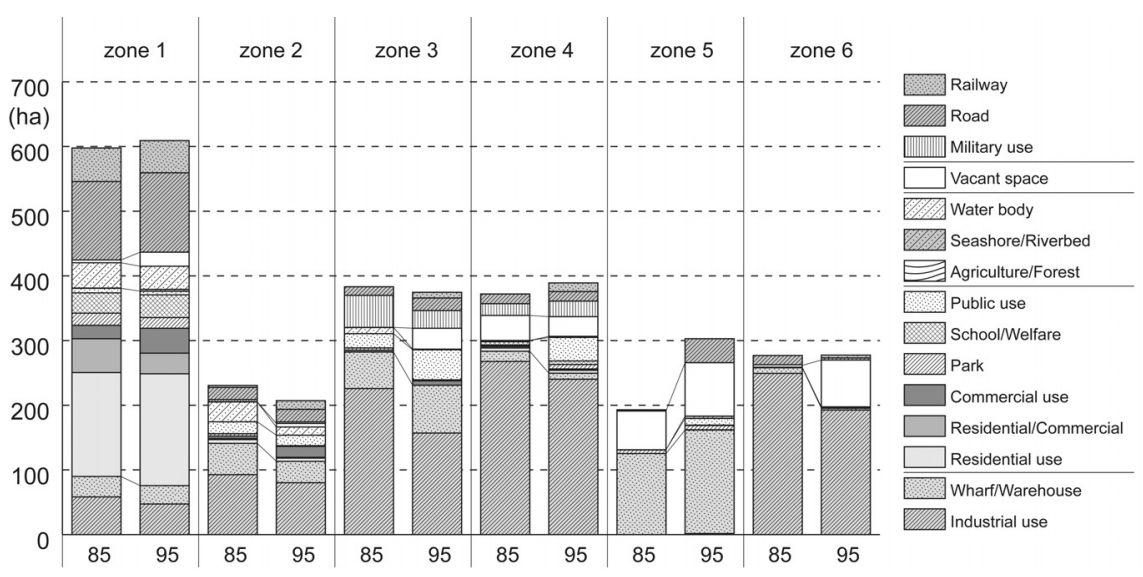

Figure 4: $\quad$ Change of land use in six zones of KIA, City of Yokohama [7].

\subsubsection{Transportation}

Public transport in KIA is limited. Passenger railway constructed mainly for factory workers connects some parts of zone 4 with JR (Japan Railway) Tsurumi and Hamakawasaki stations, but the service is limited compared to average passenger railway services in Tokyo region. To improve access by railway, utilization of the existing freight tracks for passenger services is under consideration, but the discussion has been stagnant since the area's land use plan is still not clear enough. On the other hand, arterial roads for cars and trucks have already been constructed and will be extended in the future including the connection to Yokohama Ring Road, Route 357, Tsurumi Waterfront Arterial Road and several connections to the inland urban area. These road extensions are needed to mitigate existing traffic congestions and accommodate more traffic in the future (Figure 3). 


\subsubsection{Canals, green spaces and historic structures}

In KIA, there are canals of different widths and the total length of the seawalls is nearly $70 \mathrm{~km}$. Some of the seawalls are not used for industrial purposes or covered by green thus providing opportunities for redevelopment with high level of amenity [8]. Historic industrial structures such as shipyards, factories and warehouses can be found in some sites. These are valuable resources for urban regeneration.

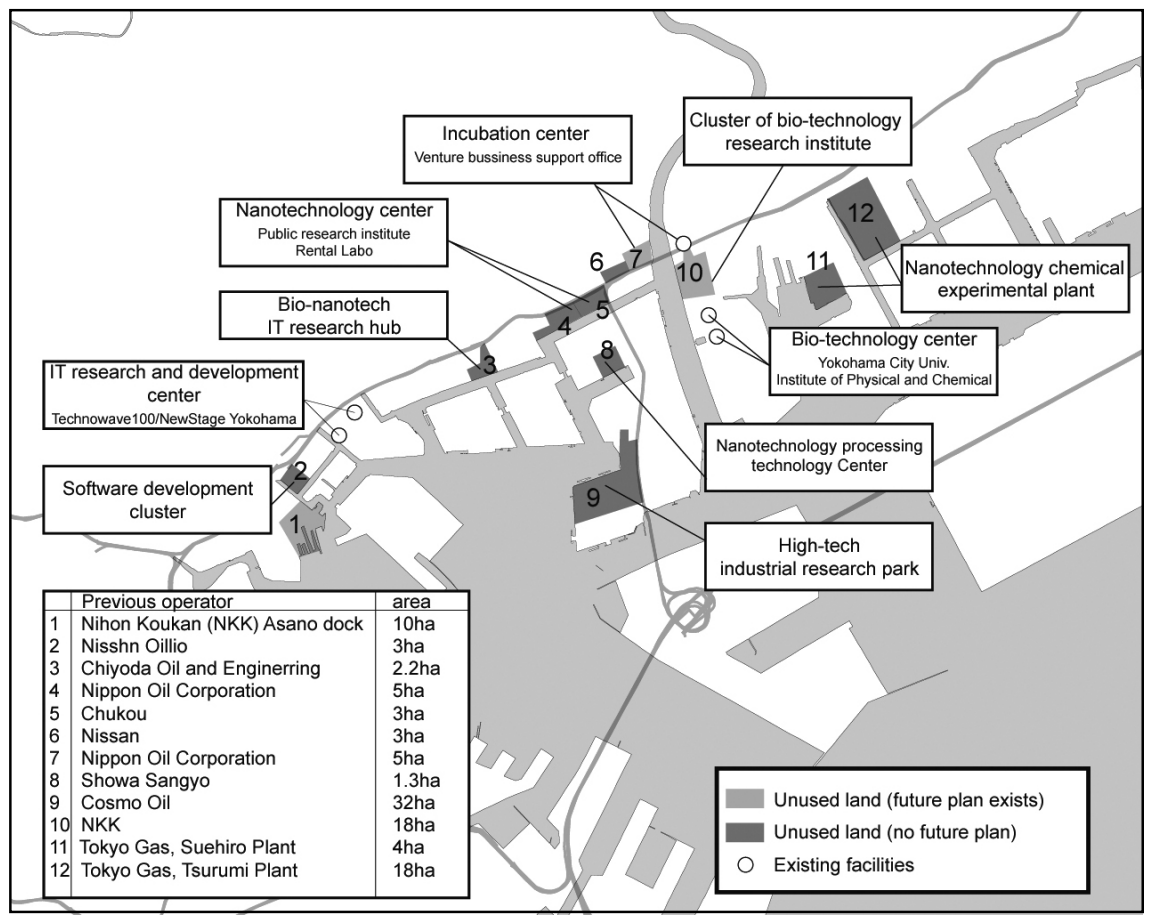

Figure 5: $\quad$ Underutilized sites and their proposed land use transition [7].

\subsubsection{Environment}

KIA has been a largest polluter to the regional environment. In recent years, more efforts have been called for to address the slow improvement on the regional environmental quality but a large improvement has been made in the past through the effort of industries responding to the gradual enforcement of national legislations. For instance, $80 \%$ of nitrogen oxides and $98 \%$ of sulphur dioxide emission loads to air were cut in the last 30-35 years [9]. On water environment, the First Total Pollution Load Control Scheme laid down by the national government in 1984 accelerated the reduction of water pollution loads $[10,11]$.

Regarding the soil contamination, accumulated survey results start revealing the situation in both Kawasaki City and Yokohama City, embracing KIA. In 2000, Kawasaki City reported 79 cases of site contamination [12] while 87 cases 
were reported in Yokohama City in 2004 [11]. This is, however, seen as a tip of icebergs and more cases are assumed to be present in KIA.

\section{Conclusion: toward the integrated methodology}

To develop a comprehensive plan for KIA, both top-down and bottom-up approaches are needed. Top-down approach involves the analysis of land use demand and industrial development potential from the regional perspective. However, this approach has its limitations since there is no organization in charge of conducting integrated regional planning for the whole Tokyo region. Each of the four prefectures has its own strategies for land use and industrial development thus making it difficult for Kanagawa Prefecture or City of Yokohama to direct industrial development KIA or estimate land use demand in KIA.

On the other hand, bottom-up approach involves site-by-site analyses of underutilized sites to estimate their redevelopment potentials and alternatives taking into account the degree of soil contamination, future land use, best-suited cleanup technologies, legal schemes and financial incentives possibly available for site remediation, historic and green resources, and location in relation to transportation facilities. An important key to starting this approach is the development of easily accessible inventory/database of contaminated properties, using public available information, to be utilized in any following planning activities. Other issues such as transportation, building types and urban design of public space can be then discussed based on the results of the above analyses.

In the process of developing a comprehensive plan for KIA, various stakeholders including city departments, property owners, business owners, potential developers, non-profit organizations and citizens should be involved in appropriate stages. It is also important to have the professionals support the process including planners and urban designers who generate alternatives based on the discussion, environmental and other experts who conduct scientific analysis and evaluate the alternatives as well as facilitators and managers who run the process efficiently and effectively.

\section{References}

[1] Ministry of Internal Affairs \& Communications, Population Census, 2005

[2] Ministry of Economy, Trade \& Industry, National Census of Manufacture, 2005

[3] Ministry of the Environment, FY2003 Summary of Enactment Situation of the Soil Contamination Countermeasures Law and Survey Results on the Cases of Soil Countermeasures Assessment and Countermeasures, 2005

[4] Geo-Environmental Protection Center, FY2003 Survey Results on "Soil Contamination Assessment and Countermeasures", 2003

[5] Kanagawa Pref., Keihin Waterfront Area Regeneration Framework, 1997

[6] City of Yokohama, Keihin Waterfront Area Regeneration Master Plan, 1997 
[7] City of Yokohama, Keihin Waterfront Area Urban Regeneration Basic Survey, 2002

[8] Center for Sustainable Urban Regeneration, The University of Tokyo, Keihin Waterfront Area Action Study 2004 Annual Report, 2004

[9] City of Yokohama, Yokohama White Paper on Environment 2004, 2004

[10] City of Yokohama, Environment in Yokohama: Annual Report on Environmental Management in Yokoyama 2005, 2005

[11] City of Yokohama, Yokohama Water Environment Plan, 1994

[12] Mainichi News Paper article, Increasing cases of site contamination in Kawasaki: shifting use of brownfield to housing, June 23, 2002 